\title{
The Fellowship of Postgraduate Medicine and the Postgraduate Medical Journal
}

I hope readers of the Postgraduate Medical Journal are sufficiently familiar with its appearance to appreciate that this month's issue looks different. The change in format is the most visible evidence that 1985 is a special year for our Journal. After many happy and productive years with Blackwell Scientific Publications we have changed our publishers, and are now looking forward to a fruitful association with The Macmillan Press.

In October we shall be publishing the 60th anniversary issue, Volume I, No. 1 having seen light of day in October 1925. Although our October 1985 issue will deal in greater detail with the history of the Journal and the changes in medicine and in postgraduate medical education over the past 60 years, it seems an appropriate time to take stock of ourselves. The Postgraduate Medical Journal is the lineal successor of the Bulletin of the Fellowship of Medicine and Postgraduate Medical Association, a combined organisation to be re-christened later the less mouth-filling Fellowship of Postgraduate Medicine. The Postgraduate Medical Association was a centrally sponsored organization charged, under the Chairmanship of Sir William Osler, with developing postgraduate medical training in the United Kingdom but was upstaged by the First World War. The Fellowship of Medicine came into being at about the time of the Armistice in 1918, and was an association of distinguished figures on the London medical scene, dedicated to making full use of the busy clinical life of London for postgraduate studies. In part this seems to have been a chauvinistic reaction to the pre-War dominance of the German and Austrian centres in the postgraduate medical field, and in part an altruistic attempt to provide a true fellowship of doctors through the Allied Nations, in particular the Englishspeaking countries of the World. The two organizations combined under the presidency of Osler to meet the sudden demand for training in civilian medicine that came with the end of the War. The Dominion and American governments gave their Medical Officers study leave on their way back from the War to civilian life. The Bulletin was published weekly from April 1919 listing all the clinics, rounds and special lectures available for those who had registered for the 'Emergency Postgraduate Course'. The first Editorial was in June of that year towards the end of the course, and just before the departure home of the very large body of American medical postgraduates. It spoke of the founders of the Fellowship's belief that a 'fraternal union of medical men of all countries can promote... the peace of the World and the future of the human race'. Such were the sentiments of our founding fathers, totally comprehensible in the context of the months after the Armistice and not to be sneered at in more cynical times.

In October 1925 the Bulletin became the Postgraduate Medical Journal which for many years contained mainly clinical review articles as well as details of the postgraduate courses. The Fellowship of Postgraduate Medicine always was, and remains, an organization independent of Government and University. It had a pioneering role in co-ordinating and providing an impetus to the development of postgraduate medical education in London and probably in the United Kingdom. With the establishment of other organizations such as the British Postgraduate Medical Federation and the Postgraduate Centre movement in hospitals throughout the land as well as the endeavours of the Royal Colleges and the Faculties, its role has inevitably changed. The last course organized by the Fellowship took place in 1974. Today the Postgraduate Medical Journal is the Fellowship's vehicle for meeting the articles of its constitution dedicated to the promotion of postgraduate medical education. The Journal plays its role by publishing a combination of original, clinically orientated research papers, review articles, and case reports. The latter have for long been a prominent feature of the Journal's pages, and have provided many young doctors with their first medical publication. They are inevitably 'anecdotal' a word much in vogue, and used in a perjorative sense. However, it is the patients of case reports that are the building units of any clinician's total experience. As such the reports are popular, at worst provide reminders of more or less important aspects of clinical care, and at best, insights into the mechanisms of disease processes and diagnostic and therapeutic approaches. The original papers and review articles provide, of course, a historic and forward look at topics of clinical importance, taking a broader sweep of clinical experience, and using statistical techniques to assess observations. For the putative author preparation of papers for publication, and the receipt of frank, but constructively critical, referees' reports itself plays an important part in the 
training of the clinician-cum-medical scientist.

The Postgraduate Medical Journal has enjoyed a steadily increasing number of papers submitted from many countries, almost all of which continue to be submitted to peer review. The rejection rate has increased sharply in recent years, which we hope is reflected in the standard of our monthly issues.

The Postgraduate Medical Journal was an early pioneer in the now controversial field of supplement publication. These have been an important source of income for the Fellowship in its course-organizing days, and now, in contributing to the Journal and possibly for other academic endeavours with our new publishers. No doubt our regular subscribers welcome these unexpected bonuses. We have long been aware of the academic and ethical issues involved in the area of publication sponsored by commercial concerns under the imprimatur of a learned Journal. I and my predecessors have always taken a strict editorial view of material submitted from symposia which, itself, has been usually submitted to the critical peer review of open discussion. Where this has not taken place, and certainly where there is any doubt about their merit, papers are submitted to independent referees. On many occasions the sponsorship has meant solely generous contributions to the corpus of medical publications, our Supplements 3 and 4 in 1983, Eurotherapeutics I and the Festschrift for Dame Sheila Sherlock being notable recent examples. We have long been aware of the problems that publications like these can provide in adding a spare tyre or two to the corpus by duplicate publication. We have attempted to ensure that where articles are reproduced in large part their origins are clearly indicated, and they are not mistaken as original. We have also, equally clearly, not been uniformly successful.

It is not easy for a monthly journal to give the sense of immediacy that adds so much to medical journalism but we hope, with our new publication schedules, to be able to reduce the time 'in press' and expand our correspondence, postgraduate diary and conference report columns. This issue carries the first of a new series on modern imaging techniques by Dr Louis Kreel.

The other happening of 1985 to note, with a mixture of sadness and pleasure, is a move of the Journal's office from Chandos House to the Royal College of Physicians. The Royal Society of Medicine, which over the years has made and continues to make major contributions to national and international postgraduate medicine, provided the offices and much encouragement and support for the Fellowship from the start. The special lectures on the postgraduate courses were given in the Society's house. Many of those involved in the founding and early years of the Fellowship were leading lights of the RSM. The President of the RSM from 1918-20, Sir Humphrey Rolleston, was the first chairman of the Executive Committee of the Fellowship, and Mr J.Y.W. (later Sir John) MacAlister, Secretary of the RSM, was one of the honorary secretaries of the Fellowship. MacAlister, who was not medically qualified, is not only credited with seeing the need for the Fellowship and providing the inspiration and drive to achieve its creation, but was largely responsible for the foundation of the Royal Society of Medicine itself from the Medico-Chirugical Society and smaller bodies. In recent years the association of the RSM and the Fellowship has been one of landlord and tenant, but very happy one, nonetheless. We look forward tơ taking up an office in the Royal College of Physician's development in St Andrew's Place, new pastures and certainly more verdant ones for us in Regent's Park.

Finally, continuing in the Janus vein, let me take this opportunity to thank our many referees for all the work they have done for scant reward for the Journal over the years - and let them know that there is lots more to come.

B.I. Hoffbrand Editor 